\title{
Purification of Plasmodium and Babesia- infected erythrocytes using a non-woven fabric filter
}

\author{
Tao, Z.Y. ${ }^{1,2^{*}}$, Liu, W.P. ${ }^{1,2}$, Dong, J. ${ }^{3}$, Feng, X.X. ${ }^{4}$, Yao, D.W. ${ }^{4}$, Lv, Q.L. ${ }^{1}$, Ibrahim, U. ${ }^{1,2}$, Dong, J.J. ${ }^{1}$, \\ Culleton, R. ${ }^{5}$, Gu, W. ${ }^{1}$, Su, P.P. ${ }^{1}$, Tao, L. ${ }^{1}$, Li, J.Y. ${ }^{1}$, Fang, Q. ${ }^{1,2^{*}}$ and Xia, H..$^{1,2^{*}}$ \\ ${ }^{1}$ Department of Microbiology and Parasitology, Bengbu Medical College, 2600\# Donghai Avenue, \\ Bengbu 233030, China \\ ${ }^{2}$ Anhui Provincial Key Laboratory of Infection and Immunology, Bengbu Medical College, 2600\# Donghai \\ Avenue, Bengbu 233030, China \\ ${ }^{3}$ Department of Microbiology, Bengbu Center for Disease Control and Prevention, 700\# Huayuan Road, \\ Bengbu 233000, China \\ ${ }^{4}$ College of Veterinary Medicine, Nanjing Agricultural University, No.1 Weigang Road, Nanjing 210095, China \\ ${ }^{5}$ Department of Molecular Parasitology, Proteo-Science Center, Ehime University, Shitsukawa, Toon, \\ Ehime 791-0295, Japan \\ *Corresponding author e-mails: Taozhiyong@bbmc.edu.cn (Zhi-Yong Tao); fq333@sohu.com (Qiang Fang); \\ xiahui@ bbmc.edu.cn (Hui Xia) \\ Received 1 April 2020; received in revised form 9 August 2020; accepted 10 August 2020
}

\begin{abstract}
The purification of parasite-infected erythrocytes from whole blood containing leucocytes is crucial for many downstream genetic and molecular assays in parasitology. Current methodologies to achieve this are often costly and time consuming. Here, we demonstrate the successful application of a cheap and simple Non-Woven Fabric (NWF) filter for the purification of parasitized red blood cells from whole blood. NWF filtration was applied to the malaria-parasitized blood of three strains of mice, and one strain of rat, and to Babesia gibsoni parasitized dog blood. Before and after filtration, the white blood cell (WBC) removal rates and red blood cell (RBC) recovery rates were measured. After NWF filter treatment of rodent malaria-infected blood, the WBC removal rates and $\mathrm{RBC}$ recovery rates were, for Kunming mice: $99.51 \% \pm 0.30 \%$ and $86.12 \% \pm 8.37 \%$; for BALB/C mice: $99.61 \% \pm 0.15 \%$ and $80.74 \% \pm 7.11 \%$; for C57 mice: $99.71 \% \pm 0.12 \%$ and $84.87 \% \pm 3.83 \%$; for Sprague-Dawley rats: $99.93 \% \pm 0.03 \%$ and $83.30 \% \pm 2.96 \%$. Microscopy showed WBCs were efficiently removed from infected dog blood samples, and there was no obvious morphological change of $B$. gibsoni parasites. NWF filters efficiently remove leukocytes from malaria parasite-infected mouse and rat blood, and are also suitable for filtration of B. gibsoni-infected dog blood.
\end{abstract}

\section{INTRODUCTION}

Intraerythrocytic parasites such as Plasmodium and Babesia, are important pathogens of humans and animals. Malaria is a serious public health threat to humans; there are about 219 million cases a year globally (Winzeler et al., 2019). The disease is caused by the intraerythrocytic protozoan parasite Plasmodium. Babesiosis is a tickborne zoonotic protozoan parasitic disease, the symptoms of which are similar to malaria
(Moritz et al., 2016). Babesia mainly threatens livestock and companion animals.

Rodent malaria parasites are commonly used in laboratory-based studies of the disease (Craig et al., 2012). There are four species of rodent malaria parasites are used in laboratories worldwide; Plasmodium chabaudi, Plasmodium vinckei, Plasmodium yoelii and Plasmodium berghei (Huang et $a l ., 2015)$ and these are maintained in a large variety of mouse and rat strains. Rodent malaria parasites have informed studies on 
malaria pathology, cerebral malaria, antimalarial chemotherapy, malaria immunology, and vaccine development (ZuzarteLuis et al., 2014; Moussa et al., 2018; Sala et al., 2018).

Babesia gibsoni is endemic in dogs in Asia, Africa and occasionally North America and Europe. It is typically transmitted by tick bite but also by direct blood contamination during, for example, fighting (Cannon et al., 2016). Experimental passage of $B$. gibsoni to beagles is common in laboratory studies on babesiosis.

Separating Plasmodium parasite infected red blood cells (iRBC) from leucocytes in infected animal blood is often an essential procedure during laboratory investigations of Plasmodium biology, immunology, molecular biology and genomics (Grech et al., 2002; Lu et al., 2011).

There are multiple methods currently available for the removal of leucocytes from whole blood (Venkatesan et al., 2012; Mehlotra et al., 2017; Mkumbaye et al., 2017). Differential centrifugation and the flushing of blood through cellulose powder columns are commonly used methodologies as they are cheap and straightforward, but have relatively low efficacies and are timeconsuming. They also suffer from relatively low iRBC recovery rates (Tao et al., 2011). Plasmodipur $^{\mathrm{TM}}$ filter filtration is easy to perform and achieves good results but is relatively expensive, especially for large scale use (Nag et al., 2018). Magnetic separation methods are able to separate and concentrate late trophozoites, schizonts, and gametocytes, but hemozoin-loaded microphages can be recovered along with iRBCs, and separation of ring-stage parasites is not possible (Trang et al., 2004; Bhakdi et al., 2010). An optimized method using magnetic nanoparticles conjugated with patient derived antibodies was shown to separate and concentrate multi-stage parasites together, but it required extensive antibody related preparation (Tangchaikeeree et al., 2013).

We have developed a prototype nonwoven fabric filtration device (Tao et al., 2011). It is suitable for the processing of small volumes of malaria-infected human blood, with high efficiency in both WBC removal and $\mathrm{RBC}$ recovery, and it has been used successfully in research on the genetics of the human malaria parasites Plasmodium vivax and Plasmodium ovale (Ansari et al., 2016; Pearson et al., 2016). Previously, it was also shown to be effective in the laboratory, where it was used to remove leucocytes from the blood of BALB/c mice infected with $P$. yoelii (Li et al., 2016). Here, we present the results of experiments testing the effectiveness of NWF filtration for purification of iRBCs from the blood of $P$. berghei and $P$. yoelii-infected BABL/c, C57, and Kunming mice and SD rats, and from dog blood infected with $B$. gibsoni.

\section{MATERIALS AND METHODS}

\section{Laboratory animals, Parasites and NWF filters}

$\mathrm{BABL} / \mathrm{c}$, C57, Kunming mice, and SD rats were purchased from the Experimental Animal Center of Anhui Medical University (Anhui, China) (Shang et al., 2009). All mice were female, 6-8 weeks old, weighed 25-30 g; female SD rats were all 8-10 weeks old, and weighed $\sim 200 \mathrm{~g}$. All animals used in this study were maintained according to Bengbu Medical College laboratory regulations. Plasmodium yoelii and $P$. berghei parasites were maintained in mice and cryopreserved in liquid nitrogen. Beagle dogs were purchased from Qing Long Shan Laboratory Center (Nanjing, China). Babesia gibsoni was isolated from a pet dog and kept in the College of Veterinary Medicine, Nanjing Agricultural University (Nanjing, China). The NWF filters were purchased from Zhixing Bio, Co. LTD (Anhui, China), the design of filter has been improved to connect to a syringe easily. (Li et al., 2017).

\section{Infection of laboratory animals}

After propagation in mice, $1 \times 10^{6}$ iRBCs of $P$. berghei or $P$. yoelii were injected intraperitoneally to each laboratory mouse in $100 \mu \mathrm{L}$ saline $\left(1 \times 10^{7} \mathrm{iRBC}\right.$ sere injected in the case of rat infection, each group con- 
tained five animals). Parasitemia was recorded every other day from three days post-infection. Five mL of blood was taken from the B. gibsoni-infected beagle dog, and injected into a healthy dog via the cephalic vein. Blood smears were prepared and read every five days.

\section{Filtration of malaria-infected animal} blood using NWF filters

Infected mice and rats were anesthetized, and $1 \mathrm{~mL}$ blood samples were collected using a heparin anticoagulation tube. RPMI 1640 medium (Gibico, USA) was used to dilute each blood sample to $5 \mathrm{~mL}$. The suspension was aspirated into a $10 \mathrm{~mL}$ syringe, and pushed through a NWF filter. The process was finished within 1 minute. $0.5 \mathrm{~mL}$ cell suspension was collected before and after treatment for $\mathrm{WBC}, \mathrm{RBC}$, and genetic tests. Five $\mathrm{mL}$ of blood was drawn from the infected beagle dog and diluted to $10 \mathrm{~mL}$ with RPMI 1640 and filtered as above. The morphology of Plasmodium and Babesia parasites were examined by microscopy with Giemsa's solution.

\section{WBC removal and $\mathrm{RBC}$ recovery rates}

WBC counts were measured by Nageotte chamber microscopy (Brand, Wertheim, Germany) (Petersson et al., 2017). WBC removal rate $=(1-\mathrm{WBC}$ after filtration/WBC before filtration) $\times 100 \%$; RBC was determined by automated blood cell counter (Mindray, Shenzhen, China), RBC recovery rate $=\mathrm{RBC}$ after filtration $/ \mathrm{RBC}$ before filtration $\times 100 \%$.

\section{Detection of mouse DNA in NWF filter treated mouse blood}

A pair of primers (Forward: 5'-AGGCCGG TGCTGAGTATGTC-3', Reverse: 5'-TGCCT GCTTCACCACCTTCTTG-3') for detecting the GAPDH gene were synthesized by Sangon Biotech (Shanghai, China). Genomic DNA was extracted by Axyprep Multisource Genomic DNA Miniprep Kit (Axygen, Suzhou, China) from blood samples of $P$. bergheiinfected BALB/c mice before and after filtration. The DNA concentrations of the two samples were adjusted to the same concentrations $(10 \mathrm{ng} / \mathrm{\mu L})$, then were serially diluted 10 -fold from $10 \mathrm{ng} / \mathrm{\mu L}$ to $1 \times 10^{-4} \mathrm{ng} / \mathrm{\mu L}$. Ex Taq kit (Takara Bio, Shiga, Japan) was used for PCR, and the conditions were $95^{\circ} \mathrm{C}$ $5 \mathrm{~min}, 30$ cycles of $95^{\circ} \mathrm{C} 15 \mathrm{~s}, 56^{\circ} \mathrm{C} 30 \mathrm{~s}, 72^{\circ} \mathrm{C}$ $45 \mathrm{~s}$, and a final extension at $72^{\circ} \mathrm{C}$ for $5 \mathrm{~min}$. PCR products were analyzed by $1.5 \%$ agarose gel.

\section{Infection of BALB/c mice with NWF} filtered $P$. berghei-infected blood

$P$. berghei-infected mouse blood was collected and filtered aseptically as described previously, and the blood was diluted by sterile saline solution for mouse infection. Five BALB/c mice were injected intraperitoneally with $100 \mu \mathrm{L}$ RBC suspension $\left(1 \times 10^{6}\right.$ parasites $)$ respectively. After infection, blood samples were collected at days $4,5,6$, and 7 to examine the parasitemia.

\section{Ethics statement}

All animal experiments were approved by the Experimental Animal Management and Ethics Committee of Bengbu Medical College, Bengbu, China (BBMC2017-074).

\section{Statistical analysis}

The WBC removal rates, $\mathrm{RBC}$ recovery rates and $95 \%$ confidence intervals (CI) were calculated using Microsoft Excel 2003.

\section{RESULTS}

\section{Morphological characterization of parasites following NWF filtration}

After filtration with the NWF filters, the $P$. berghei and $P$. yoelii-infected mouse blood samples and B. gibsoni-infected dog blood samples were examined by microscopy with Giemsa's solution stain both in thin and thick blood films. There were no morphological changes in any parasite species observed by thin-film microscopy. There was a large reduction in the numbers of WBCs observed by microscopy in both mouse and dog blood following NWF filter treatment by thick-film microscopy (Figure 1). 


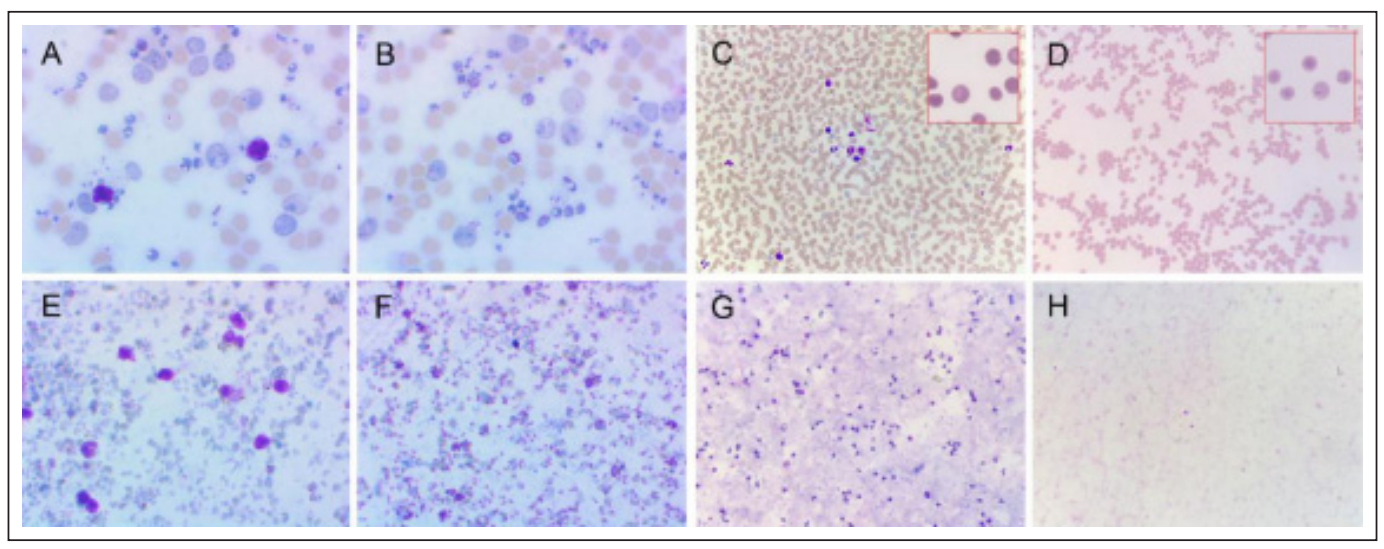

Figure 1. Microscopy of infected blood samples before and after filtration with the NWF filter.

(A) P. berghei-infected BALB/c mouse blood, thin film, before filtration $(1000 \times)$; (B) P. berghei-infected mouse blood, thin film, after filtration $(1000 \times)$; (C) B. gibsoni-infected canine blood, thin film, before filtration $(400 \times, 1000 \times$ in red rectangle); (D) B. gibsoni-infected canine blood, thin film, after filtration $(400 \times, 1000 \times$ in red rectangle); (E) P. berghei-infected blood, thick film, before filtration $(1000 \times)$; (F) P. berghei-infected blood, thick film, after filtration $(1000 \times)$; (G) B. gibsoni-infected canine blood, thick film, before filtration (400×); (H) B. gibsoni-infected dog blood, thick film, after filtration (400×).

Table 1. WBC removal and RBC recovery following NWF filtration for $P$. berghei-infected rodent blood samples

\begin{tabular}{lccc}
\hline Animals & $\mathrm{n}$ & $\begin{array}{c}\text { WBC removal rates } \\
\mathrm{X}_{ \pm} \mathrm{SD} \\
(95 \% \mathrm{CI})\end{array}$ & $\begin{array}{c}\text { RBC recovery rates } \\
\mathrm{X} \pm \mathrm{SD} \\
(95 \% \mathrm{CI})\end{array}$ \\
\hline Kunming mice & 5 & $99.51 \% \pm 0.30 \%$ & $86.12 \% \pm 8.37 \%$ \\
& & $(99.14 \%-99.87 \%)$ & $(75.73 \%-96.52 \%)$ \\
BALB/c mice & 5 & $99.61 \% \pm 0.15 \%$ & $80.74 \% \pm 7.11 \%$ \\
& & $(99.43 \%-99.80 \%)$ & $(71.91 \%-89.57 \%)$ \\
C57 mice & 5 & $99.71 \% \pm 0.12 \%$ & $84.87 \% \pm 3.83 \%$ \\
& & $(99.56 \%-99.85 \%)$ & $(80.11 \%-89.63 \%)$ \\
SD rats & 5 & $99.93 \% \pm 0.03 \%$ & $83.30 \% \pm 2.96 \%$ \\
& & $(99.90 \%-99.97 \%)$ & $(79.62 \%-86.97 \%)$ \\
\hline
\end{tabular}

\section{WBC removal and $\mathrm{RBC}$ recovery efficacy using NWF filters}

BALB/c, C57, Kunming mice and SD rat groups ( $\mathrm{n}=5$ each) were included. After NWF filtration the WBC removal rates were all above $99.5 \%$, and the $\mathrm{RBC}$ recovery rates were all above $80.0 \%$ (Table 1 ).

Semi-quantitative measurement of mouse GAPDH gene copy number in whole blood pre and post NWF filtration For $P$. berghe $i$-infected BALB/c mice, semiquantitative PCR gel analysis showed that the mouse GAPDH gene copy number in blood decreased about 100 fold following NWF filtration (Figure 2).

\section{Infection of mice with filtered $P$. berghei iRBC}

Two groups of BALB/c mice ( $\mathrm{n}=5$, each) were infected with $1 \times 10^{6}$ parasites of filtered or unfiltered $P$. berghei iRBC derived from the same blood sample. All mice became infected, and the parasitemia of two groups were similar between day 4 to day 7 (Figure 3). 


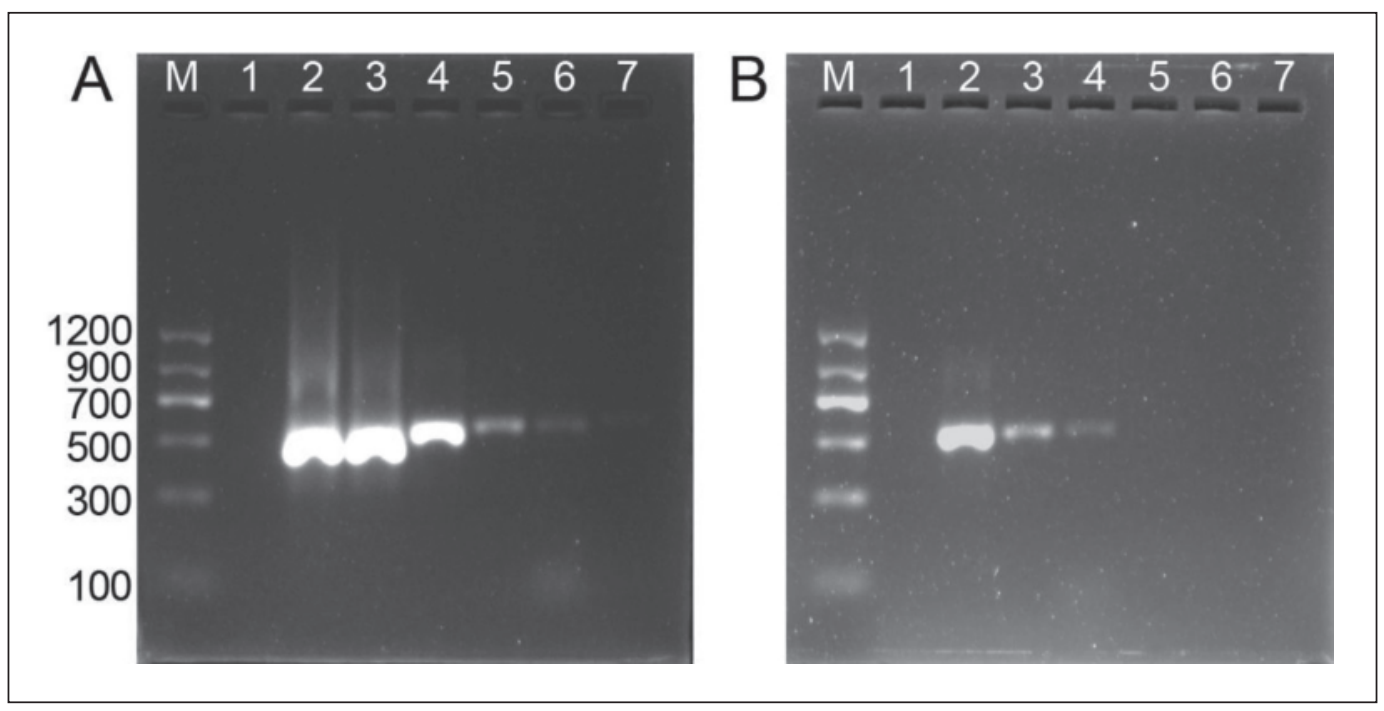

Figure 2. Effect of NWF filtration on GAPDH gene detection determined by PCR.

(A) Before filtration; (B) After filtration; (M) DNA marker; (A1, B1) Negative control; (A2, B2) 10 ng/ $\mathrm{LL}$ DNA; (A3, B3) $1 \mathrm{ng} / \mathrm{\mu L}$ DNA; (A4, B4) $0.1 \mathrm{ng} / \mathrm{\mu L}$ DNA; (A5, B5) $0.01 \mathrm{ng} / \mathrm{\mu L}$ DNA; (A6, B6) $0.001 \mathrm{ng} / \mathrm{\mu L}$ DNA; (A7, B7) $0.0001 \mathrm{ng} / \mu \mathrm{L}$ DNA.

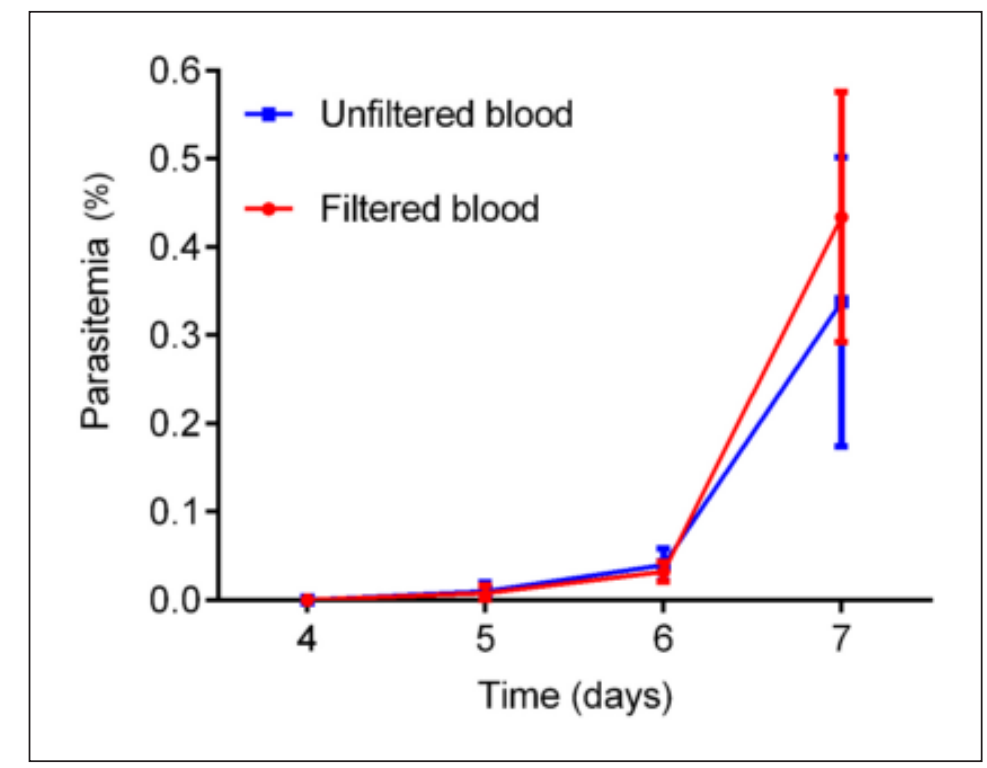

Figure 3. Parasitemia in mice infected with NWF filtered $P$. berghei blood. The parasitemia of the two groups are not significantly different $(\mathrm{P}>0.05)$.

\section{DISCUSSION}

Removal of WBCs from intraerythrocytic parasite-infected blood samples is a crucial step in many laboratory studies on intraerythrocytic parasites (Auburn et al., 2011; Roobsoong et al., 2015; Thomson-Luque et al.,
2017). The most commonly used methods include differential centrifugation, filtration, cellulose column filtration, magnetic separation, and flow cytometric isolation. Among these, filtration is particularly suitable for in vitro antimalarial drug sensitivity experiments as it is simple to 
perform, and leukocyte removal is efficient (Janse et al., 1994; Lu et al., 2011). As currently available filters are relatively expensive, however, a cheaper effective alternative is desirable. Filtration by cellulose powder column is cost-effective, but is time consuming not only in preparation, but also in the filtration process. Moreover, when dealing with small volumes of mouse blood, the recovery rate of RBCs is often low, as it is affected by column bed volume, dilution and wash conditions.

We previously showed that a prototype NWF filter was suitable for the treatment of Plasmodium vivax-infected human blood, with WBC removal rates similar to cellulose column filtration, but with the advantage that $\mathrm{RBC}$ recovery rates were significantly higher (Tao et al., 2011). In addition, the NWF filter method was as fast and simple as Plasmodipur ${ }^{\mathrm{TM}}$ filtration; with the added benefit that filtered parasites remain viable (Li et al., 2017; Lu et al., 2017).

Here we have shown that the NWF filter can be used to deplete leucocytes from the blood of P. berghei-infected BALB/c, C57, Kunming mice and SD rats. Greater than 99.5\% leukocytes were removed from these four species of rodent blood samples after treatment with a NWF filter. PCR semi-quantification of the BALB/c mouse housekeeping gene GPADH showed a 100fold decrease in copy number estimation in filtered blood compared to unfiltered blood.

Both WBC counts and PCR amplification revealed the high efficiency of WBC removal from $P$. berghei-infected rodent animal blood using a NWF filter. The RBC recovery rate for rodent blood following NWF filtration was greater than $80.0 \%$, lower than that previously achieved with $P$. vivax-infected human blood (95.0\%). The reason for this difference is due to differences in the initial blood sample volume used, with five times more blood used in the human malaria sample compared to that from mice. In the case of human blood sample, the amount of blood cells absorbed by the fabric pad had reached saturation, whereas this had not occurred in the case of the lower-volume rodent blood sample. In order to achieve and increased yield of recovered blood cells, a larger volume of eluent may be used.

Microscopy of Giemsa's solution stained blood films showed that as well as efficiently removing WBCs, rodent malaria parasites and canine Babesia parasites in the recovered iRBCs were morphologically similar before and after NWF filtration. The subsequent infection of mice with $P$. berghei iRBCs that had passed through the filter demonstrates maintenance of the parasite viability following filtration. The use of the NWF to remove WBCs from intraerythrocytic stage parasite-infected blood, is therefore, an efficient and cost-effective alternative to current purification methods.

\section{Conflict of interest}

The authors declare that they have no competing interests.

Acknowledgements. This work was supported by grants from the Scientific Research Innovation Team Project of Anhui Colleges and Universities (2016-40), the Anhui Provincial and National College Student's Innovation and Entrepreneurship Training Program (AH201610367020, 201810367026), and the Key Program of Natural Science Project of Anhui Higher Education Institutions (KJ2017A222).

The authors thank Dr. Jiu Jiang of Drexel University for helpful discussion and preparing manuscript. The authors also thank the undergraduate students of Bengbu Medical College who participated in the Innovation Training Program for taking care of laboratory animals.

\section{REFERENCES}

Ansari, H.R., Templeton, T.J., Subudhi, A.K., Ramaprasad, A., Tang, J., Lu, F., Naeem, R., Hashish, Y., Oguike, M.C., Benavente, E.D., Clark, T.G., Sutherland, C.J., Barnwell, J.W., Culleton, R., Cao, J. \& Pain, A. (2016). Genome-scale comparison of expanded gene families in Plasmodium ovale wallikeri and Plasmodium ovale curtisi with 
Plasmodium malariae and with other Plasmodium species. International Journal for Parasitology 46(11): 685696.

Auburn, S., Campino, S., Clark, T.G., Djimde, A.A., Zongo, I., Pinches, R., Wanske, M., Mangano, V., Alcock, D., Anastasi, E., Maslen, G., Macinnis, B., Rockett, K., Modiano, D., Newbold, C.I., Doumbo, O.K., Ouédraogo, J.B. \& Kwiatkowski, D.P. (2011). An effective method to purify Plasmodium falciparum DNA directly from clinical blood samples for whole genome high-throughput sequencing. PLoS One 6(7): e22213.

Bhakdi, S.C., Ottinge, A., Somsri, S., Sratongno, P., Pannadaporn, P., Chimma, P., Malasit, P., Pattanapanyasat, K. \& Neumann, H.P. (2010). Optimized high gradient magnetic separation for isolation of Plasmodiuminfected red blood cells. Malaria Jourmal 9: 38 .

Cannon, S.H., Levy, J.K., Kirk, S.K., Crawford, P.C., Leutenegger, C.M., Shuster, J.J., Liu, J. \& Chandrashekar, R. (2016). Infectious diseases in dogs rescued during dogfighting investigations. Veterinary Journal (London, England: 1997) 211: 64-69.

Craig, A.G., Grau, G.E., Janse, C., Kazura, J.W., Milner, D., Barnwell, J.W., Turner, G. \& Langhorne, J. (2012). The role of animal models for research on severe malaria. PLoS Pathogens 8(2): e1002401.

Grech, K., Martinelli, A., Pathirana, S., Walliker, D., Hunt, P. \& Carter, R. (2002). Numerous, robust genetic markers for Plasmodium chabaudi by the method of amplified fragment length polymorphism. Molecular and Biochemical Parasitology 123(2): 95-104.

Huang, B.W., Pearman, E. \& Kim, C.C. (2015). Mouse Models of Uncomplicated and Fatal Malaria. Bio-Protocol 5(13): e1514. Janse, C.J., Camargo, A., Del Portillo, H.A., Herrera, S., Kumlien, S., Mons, B., Thomas, A. \& Waters, A.P. (1994). Removal of leucocytes from Plasmodium vivax-infected blood. Annals of Tropical Medicine and Parasitology 88(2): 213-216.
Li, J., Cai, B., Qi, Y., Zhao, W., Liu, J., Xu, R., Pang, Q., Tao, Z., Hong, L., Liu, S., Leerkes, M., Quiñones, M. \& Su, X.Z. (2016). TR introns, antisense RNA and differentially spliced transcripts between Plasmodium yoelii subspecies. Malaria Journal 15: 30.

Li, J., Tao, Z., Li, Q., Brashear, A., Wang, Y., Xia, H., Fang, Q. \& Cui, L. (2017). Further evaluation of the NWF filter for the purification of Plasmodium vivaxinfected erythrocytes. Malaria Journal 16: 201.

Lu, F., Gao, Q., Chotivanich, K., Xia, H., Cao, J., Udomsangpetch, R., Cui, L. \& Sattabongkot, J. (2011). In vitro antimalarial drug susceptibility of temperate Plasmodium vivax from central China. The American Journal of Tropical Medicine and Hygiene 85(2): 197-201.

Lu, F., Zhang, M., Culleton, R.L., Xu, S., Tang, J., Zhou, H., Zhu, G., Gu, Y., Zhang, C., Liu, Y., Wang, W., Cao, Y., Li, J., He, X., Cao, J. \& Gao, Q. (2017). Return of chloroquine sensitivity to Africa? Surveillance of African Plasmodium falciparum chloroquine resistance through malaria imported to China. Parasites \& Vectors 10: 355.

Mehlotra, R.K., Blankenship, D., Howes, R.E., Rakotomanga, T.A., Ramiranirina, B., Ramboarina, S., Franchard, T., Linger, M.H., Zikursh-Blood, M., Ratsimbasoa, A.C., Zimmerman, P.A. \& Grimberg, B.T. (2017). Long-term in vitro culture of Plasmodium vivax isolates from Madagascar maintained in Saimiri boliviensis blood. Malaria Journal 16: 442.

Mkumbaye, S.I., Minja, D.T., Jespersen, J.S., Alifrangis, M., Kavishe, R.A., Mwakalinga, S.B., Lusingu, J.P., Theander, T.G., Lavstsen, T. \& Wang, C.W. (2017). Cellulose filtration of blood from malaria patients for improving ex vivo growth of Plasmodium falciparum parasites. Malaria Journal 16: 69. 
Moritz, E.D., Winton, C.S., Tonnetti, L., Townsend, R.L., Berardi, V.P., Hewins, M.E., Weeks, K.E., Dodd, R.Y. \& Stramer, S.L. (2016). Screening for Babesia microti in the U.S. Blood Supply. The New England Journal of Medicine 375: 2236-2245.

Moussa, E., Huang, H., Ahras, M., Lall, A., Thezenas, M.L., Fischer, R., Kessler, B.M., Pain, A., Billker, O. \& Casals-Pascual, C. (2018). Proteomic profiling of the brain of mice with experimental cerebral malaria. Journal of Proteomics 180: 61-69.

Nag, S., Kofoed, P.E., Ursing, J., Lemvigh, C.K., Allesøe, R.L., Rodrigues, A., Svendsen, C.A., Jensen, J.D., Alifrangis, M., Lund, O. \& Aarestrup, F.M. (2018). Direct wholegenome sequencing of Plasmodium falciparum specimens from dried erythrocyte spots. Malaria Journal 17: 91.

Pearson, R.D., Amato, R., Auburn, S., Miotto, O., Almagro-Garcia, J., Amaratunga, C., Suon, S., Mao, S., Noviyanti, R., Trimarsanto, H., Marfurt, J., Anstey, N.M., William, T., Boni, M.F., Dolecek, C., Hien, T.T., White, N.J., Michon, P., Siba, P., Tavul, L. \& Kwiatkowski, D.P. (2016). Genomic analysis of local variation and recent evolution in Plasmodium vivax. Nature Genetics 48(8): 959-964.

Petersson, A. \& Ekblom, K. (2017). Methods for counting residual leukocytes in leukocyte-depleted plasma-a comparison between a routine hematology instrument, the Nageotte chamber, flow cytometry, and a fluorescent microscopy analyzer. Transfusion 57(5): 1192-1198.

Roobsoong, W., Tharinjaroen, C.S., Rachaphaew, N., Chobson, P., Schofield, L., Cui, L., Adams, J.H. \& Sattabongkot, J. (2015). Improvement of culture conditions for long-term in vitro culture of Plasmodium vivax. Malaria Journal 14: 297.
Sala, K.A., Angrisano, F., Da, D.F., Taylor, I.J. Churcher, T.S. \& Blagborough, A.M. (2018). Immunization with Transgenic Rodent Malaria Parasites Expressing Pfs25 Induces Potent TransmissionBlocking Activity. Scientific Reports 8(1): 1573.

Shang, H., Wei, H., Yue, B., Xu, P. \& Huang, H. (2009). Microsatellite analysis in two populations of Kunming mice. Laboratory Animals 43(1): 34-40.

Tangchaikeeree, T., Jangpatarapongsa, K., Polpanich, D., Thiramanas, R., Pornjarone, A., Udnaen, S., Udomsangpetch, R. \& Tangboriboonrat, P. (2013). Enrichment of malaria parasites by antibody immobilized magnetic nanoparticles. Journal of Biomedical Nanotechnology 9(10): 1768-1775.

Tao, Z.Y., Xia, H., Cao, J. \& Gao, Q. (2011). Development and evaluation of a prototype non-woven fabric filter for purification of malaria-infected blood. Malaria Journal 10: 251.

Thomson-Luque, R., Shaw Saliba, K., Kocken, C. \& Pasini, E.M. (2017). A Continuous, Long-Term Plasmodium vivax In vitro Blood-Stage Culture: What Are We Missing? Trends in Parasitology 33(12): 921-924.

Trang, D.T., Huy, N.T., Kariu, T., Tajima, K. \& Kamei, K. (2004). One-step concentration of malarial parasite-infected red blood cells and removal of contaminating white blood cells. Malaria Journal 3: 7 .

Venkatesan, M., Amaratunga, C., Campino, S., Auburn, S., Koch, O., Lim, P., Uk, S., Socheat, D., Kwiatkowski, D.P., Fairhurst, R.M. \& Plowe, C.V. (2012). Using CF11 cellulose columns to inexpensively and effectively remove human DNA from Plasmodium falciparum-infected whole blood samples. Malaria Journal 11: 41.

Winzeler, E.A. (2019). A roadmap for malaria research. Science 365(6455): 753-754.

Zuzarte-Luis, V., Mota, M.M. \& Vigário, A.M. (2014). Malaria infections: what and how can mice teach us. Journal of Immunological Methods 410: 113-122. 